\title{
A Single Stage Surgically Facilitated Rapid Orthodontic Technique with Alveolar Bone Augmentation in the Treatment of Various Dental Malocclusions: Case Series \\ Neetha J Shetty* \\ Deptartment of Periodontology, Manipal College of Dental Sciences, Manipal University, India
}

\begin{abstract}
Background: Corticotomy when done on the bone over a root prominence can cause its demineralization, optimizing the response to applied orthodontic forces. This, when combined with augmentation of the alveolar bone can increase its volume and can also correct osseous dehiscences, and fenestrations over root surfaces. Here are cases that demonstrate the usefulness of periodontally accelerated orthodontic procedure in orthodontic treatment for the correction of various dental malocclusions.

Materials and methods: Orthodontic tooth movement combined with elevation of full-thickness flap, selective decortication, and ostectomy of alveolar bone, followed by bone grafting to accomplish the desired complete orthodontic treatment.

Results: The desired outcome of the PAOO as demonstrated by rapid tooth movement was observed in all the cases.

Conclusion: An efficient and stable orthodontic tooth movement can be achieved with the periodotally accelerated osteogenic orthodontics technique. With this technique, the teeth can be moved in one third to one fourth the time required for traditional orthodontics alone. Maintaining an adequate blood supply is an essential element in this technique as this is a physiologically based treatment consistent with a regional acceleratory phenomenon.
\end{abstract}

Keywords: Corticotomy; Orthodontics; PAOO; Periodontal regeneration

\section{Introduction}

Ideal esthetic, restorative and reconstructive dental treatments are facilitated by favorably positioned teeth and an enhanced muco-gingival complex. Patients requiring comprehensive dental rehabilitation, correction of malocclusion or mutilated occlusion, frequently require orthodontic treatment in order to obtain a predictable, esthetic and functional treatment outcome. However, these patients have to undergo orthodontic treatment for 2-3 years which can be an obstacle in undergoing ideal rehabilitative dental care. By combining corticotomy with orthodontic treatment the time required for traditional orthodontic therapy is reduced by $60-75 \%$. Here is a series of various orthodontic cases that have been treated successfully with satisfactory results within a short span of time using the PAOO technique.

\section{Case Series}

Presented below are cases that were treated in the Department of Periodontology, Manipal College of Dental Sciences, Manipal University, Mangalore. The cases were referred from the department of Orthodontics for periodontally accelerated tooth movement, as the desirable tooth movement was not achieved with the conventional orthodontic therapy over 2 years. All the 3 patients were systemically healthy and aged between $18-25$ years.

\section{Case-1 (bimaxillary protrusion)}

Patient had a Class II skeletal base with proclined and forwardly placed maxilla and mandible. The molar relation was class II on both sides with a class I canine relation on both side and a spacing of $15 \mathrm{~mm}$ in lower arch and spacing of $1 \mathrm{~mm}$ in upper arch. Anterior mandible was Bolton's excess of $1.6 \mathrm{~mm}$. Ashley Howe's analysis showeds that arch expansion was not possible and it was a boderline case. Arch
Perimeter Analysis Showed an excess of $12 \mathrm{~mm}$. Lower midline was shifted to the left by $1 \mathrm{~mm}$ (Figures 1 and 2).

\section{Case-2 (space closure)}

Patient reported with proclined and forwardly placed maxilla and mandible and was diagnosed with dental class II relationship with spacing between all the anterior teeth. The patient was referred for PAOO for the closure of spaces (Figures 3 and 4).

\section{Case-3 (intrusion)}

Patient was diagnosed as having unilateral scissor bite on left side because of supra eruption of upper left posterior segment and lingual rolling in of lower left posterior segment. She was referred for PAAO procedure for intrusion of left posterior segment using temporary anchorage device i.e miniscrew implant and also uprighting of lower left posterior segment (Figures 5 and 6).

The procedure for all cases was as described below:

\section{Flap design}

A full thickness flap in the most coronal aspect of the flap with a split-thickness dissection performed in the apical portions. The

*Corresponding author: AShetty NJ, Associate Professor, Department of Periodontology, Manipal College of Dental Sciences, Manipal University, Mangalore-575001, India, E-mail: neetharajesh2000@gmail.com

Received April 29, 2015; Accepted July 24, 2015; Published July 28, 2015

Citation: Shetty NJ (2015)A Single Stage Surgically Facilitated Rapid Orthodontic Technique with Alveolar Bone Augmentation in the Treatment of Various Dental Malocclusions: Case Series. Surgery Curr Res 5: 241. doi:10.4172/21611076.1000241

Copyright: ( 2015 Shetty NJ. This is an open-access article distributed under the terms of the Creative Commons Attribution License, which permits unrestricted use, distribution, and reproduction in any medium, provided the original author and source are credited. 
Citation: Shetty NJ (2015)A Single Stage Surgically Facilitated Rapid Orthodontic Technique with Alveolar Bone Augmentation in the Treatment of Various Dental Malocclusions: Case Series. Surgery Curr Res 5: 240. doi:10.4172/2161-1076.1000241

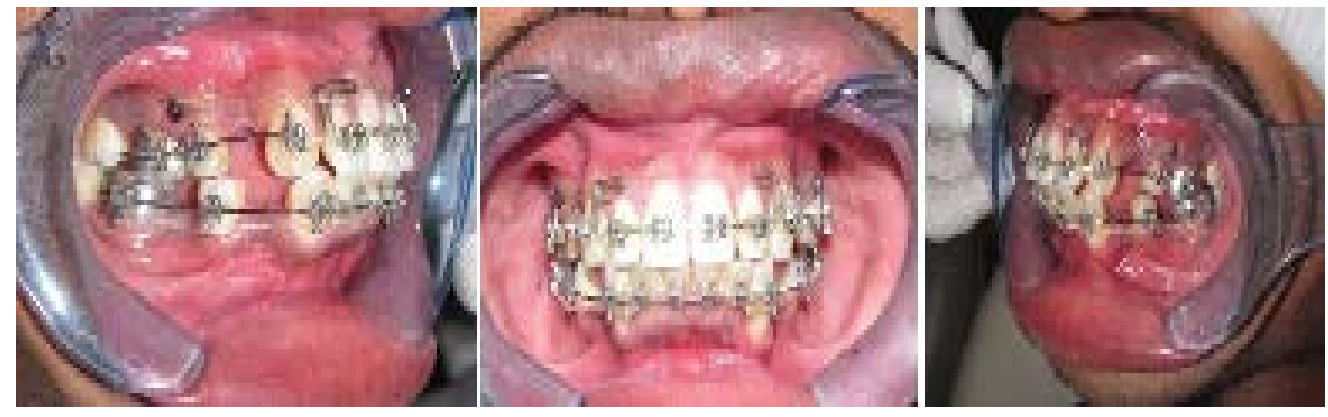

Figure 1: Bimaxillary protrusion Pre-treatment photographs.
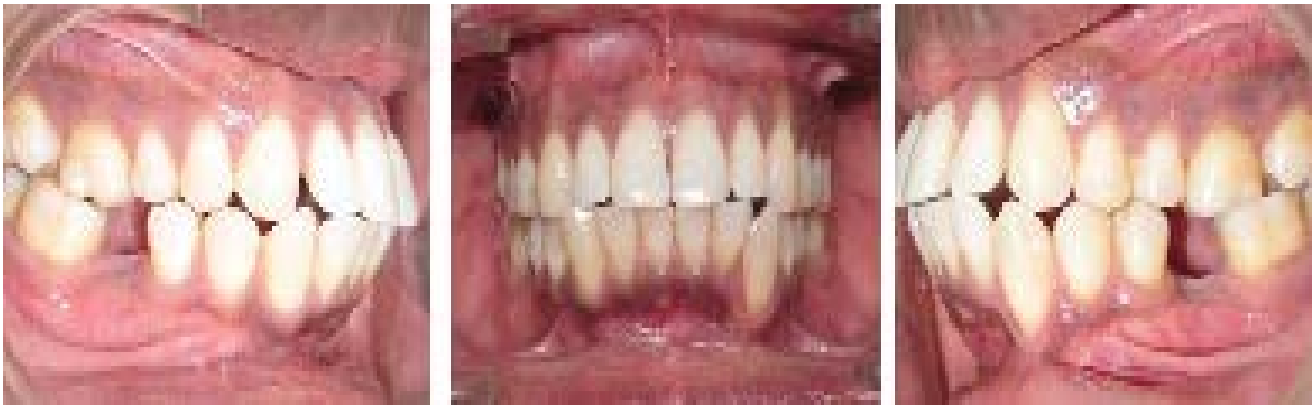

Figure 2: Bimaxillary protrusion Pre-treatment photographs.

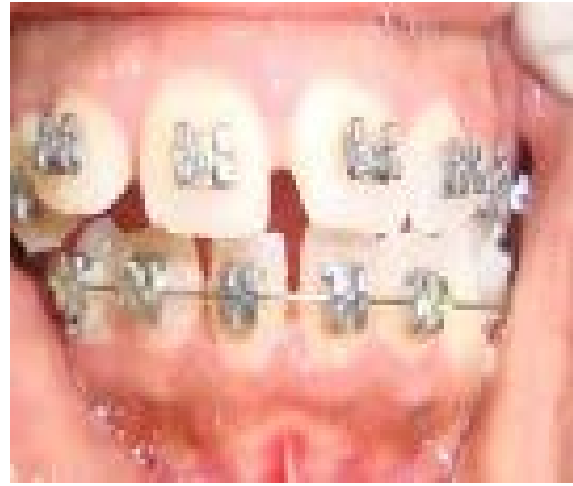

Figure 3: Space Closure pre-operation.

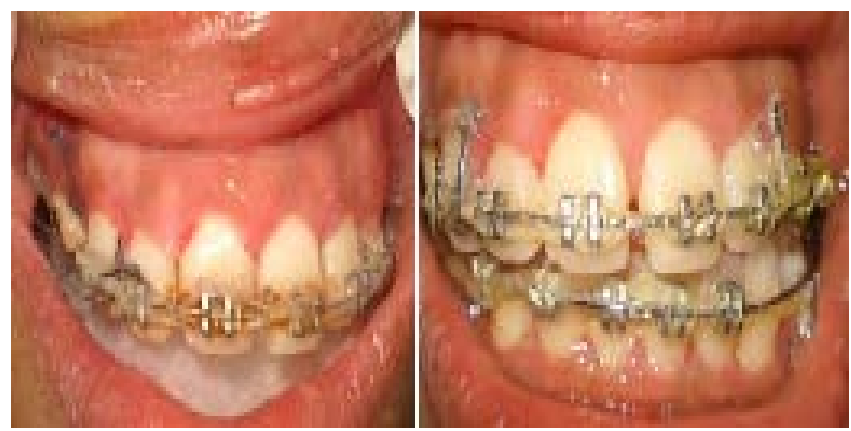

Figure 4: Space Closure one week post operation and one month post operation.

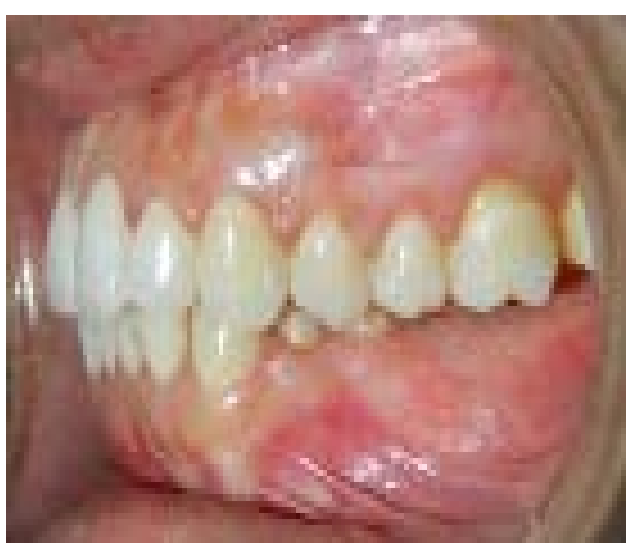

Figure 5: Intrusion Pre-Operation

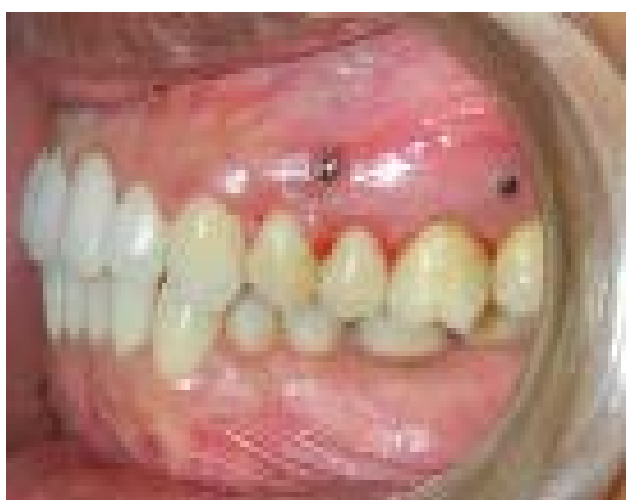

Figure 6: Intrusion Post-Operation. 
split-thickness dissection provides mobility of the flap so that it may be sutured with minimal tension. The flap is extended mesially and distally beyond the corticotomy areas to reduce the need for vertical releasing incisions. The initial incision is carried out on both surfaces of the alveolus (Figures 7 and 8).

\section{Decortication}

The purpose of the decortication is to initiate the RAP response and not to create movable bone segments. By use of No. 1 or No. 2 round burs in a high-speed handpiece, decortications are made in the alveolar bone. The corticotomies are placed on both the labial and lingual (palatal) aspects of the alveolar bone. Vertical grooves are placed in the interradicular space, midway between the root prominences in the alveolar bone. This groove extends from a point 2 to $3 \mathrm{~mm}$ apical to the crest of the bone to a point $2 \mathrm{~mm}$ beyond the apices of the roots. These vertical corticotomies are then connected with a circular-shaped corticotomy. Care is taken not to extend the cuts near any neurovascular structures. However, if this bone is estimated to be less than 1 to $2 \mathrm{~mm}$ in thickness, these perforations are omitted to ensure no damage to the radicular surface (Figure 9).

\section{Particulate grafting}

Grafting is done in the areas that have undergone corticotomies. The volume of the graft material used is dictated by the direction and amount of tooth movement to be achieved, the pretreatment thickness of the alveolar bone, and the need for labial support by the alveolar bone.

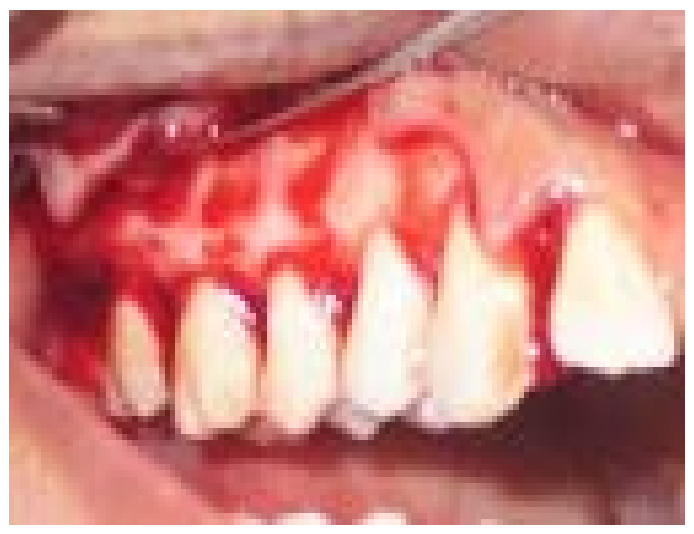

Figure 7: Flap elevation on labial aspect

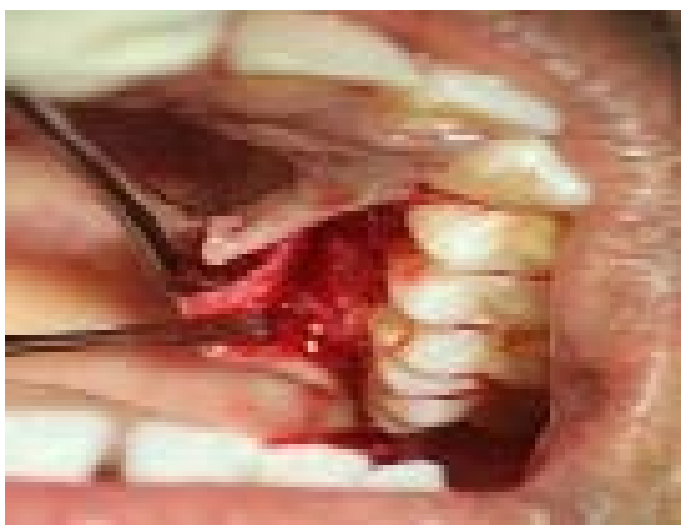

Figure 8: Flap elevation on palatal aspect.

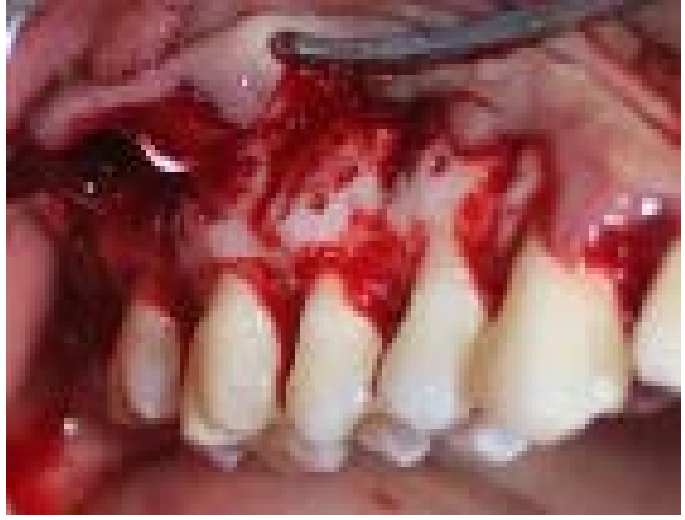

Figure 9: Vertical Corticotomy grooves with holes on the buccal aspect.

Decalcified freeze-dried bone allograft is placed on the area of corticotomy. The decorticated bone helps in retaining the graft material (Figure 10)

\section{Closure techniques}

Primary closure of the gingival flaps without excessive tension and graft containment are achieved with independent interrupted sutures (Figure 11). The type of sutures used is determined by the thickness of the tissue. The sutures that approximate the tissues at the midline are placed first to ensure the proper alignment of the papillae. The remaining inter-proximal sutures are placed next, followed by the closure of any vertical incisions. Periodontal dressing was given. The sutures were usually left in place for 1 week.

\section{Post-op patient management}

The choice of antibiotics and anti-inflammatory drugs to be prescribed depends on the clinician's preference. Patient is asked to apply icepack on the affected area as it may decrease the severity of any possible postoperative swelling or edema. The patients were asked to return for postsurgical evaluation after 1-2 weeks for the first 2 months and mild orthodontic forces were applied, then monthly thereafter.

\section{Discussion}

Unlike usual corticotomy, PAOO cuts into the bone and decorticates it, thereby removing some of the bone's external surface. The bone then goes through a phase of osteopenia, where its mineral content is temporarily reduced. Now, the tissues of the alveolar bone release rich deposits of calcium, and soon, new bone begins to mineralize in about 20 to 55 days. As the bone is still in a transient state with the bone being softer and less resistance to forces, braces can move the teeth very quickly. Studies have shown that the results of PAOO are as stable and long-lasting as conventional orthodontic braces [4-9].

Corticotomy facilitated orthodontics have been employed in various forms over the past to speed up orthodontic treatment. Kole [5-7] was the first to introduce this as a means for rapid tooth movement1, 1a, 1b. The cortical plates of bone were believed to cause main resistance to tooth movement and by disrupting its continuity, orthodontics could be completed in much less time than normally expected. Kole's procedure included the reflection of full thickness flaps to expose buccal and lingual alveolar bone, followed by interdental cuts through the cortical bone, barely penetrating the medullary bone. These vertical interdental cuts were joined by subapical horizontal cuts which followed osteotomy style, penetrating the full thickness of the 
Citation: Shetty NJ (2015)A Single Stage Surgically Facilitated Rapid Orthodontic Technique with Alveolar Bone Augmentation in the Treatment of Various Dental Malocclusions: Case Series. Surgery Curr Res 5: 240. doi:10.4172/2161-1076.1000241

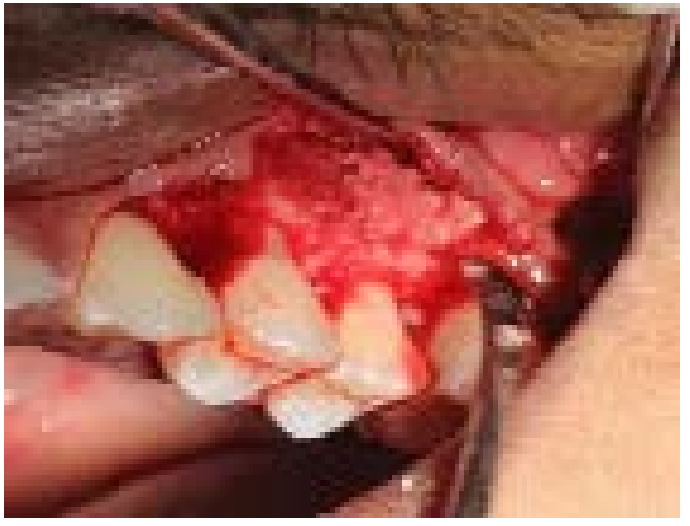

Figure 10: Graft placed in Corticotomy sites.

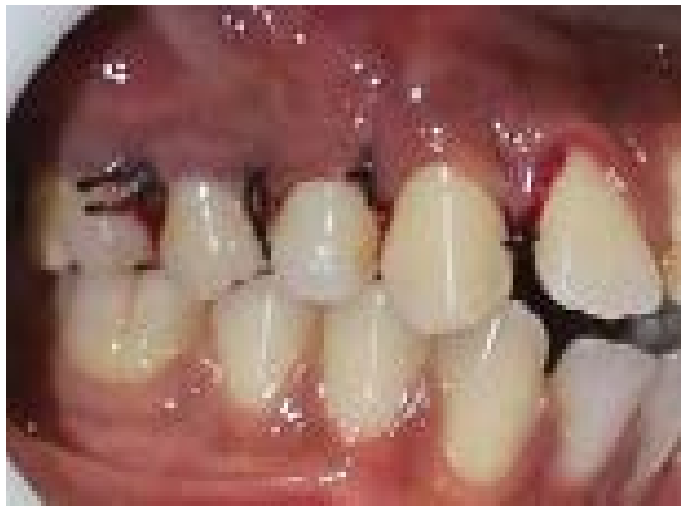

Figure 11: Sutures placed

alveolus. According to him, as the blocks of bone was being moved rather than the individual teeth, the root resorption would not occur and retention time would be minimized. But, because of the invasive nature of this technique, it was never accepted.

Wilcko et al. [4-9] recently introduced a more surgical orthodontic therapy which included the innovative strategy of combining corticotomy surgery with alveolar grafting in a technique referred to as accelerated osteogenic orthodontics (AOO) and more recently to as Periodontally accelerated osteogenic orthodontics (PAOO) [8]. For the 3 cases presented here, the procedure given by Wilko has been followed. In the above 3 cases, the desired orthodontic results have been achieved in a short period of time.

This technique has been reported to be safe, effective, extremely predictable, associated with less root resorption and reduced treatment time, and can reduce the need for orthognathic surgery in certain situations [3-13].
PAOO has expanded the realm of traditional orthodontic tooth movement (OTM) protocols. The spirit of interdisciplinary collaboration in orthodontics incorporates periodontal tissue engineering and regenerative surgery to expedite orthodontic tooth movement with reduced side-effects like root resorption, tooth devitalization, relapse, inadequate basal bone and bacterial time load factors like caries and infection [14]. This technique can be a "WINWIN situation" with an increasing number of adults considering orthodontic treatment.

\section{References}

1. Wilcko WM, Wilcko T, Bouquot JE, Ferguson DJ (2001) Rapid orthodontics with alveolar reshaping: two case reports of decrowding. Int J Periodont Restorat Dent 21: 9-19.

2. Wilcko MW, Ferguson DJ, Bouquot JE, Wilcko MT (2003) Rapid orthodontic

3. decrowding with alveolar augmentation: case report. World J Orthod 4: 197205

4. Wilcko MT, Wilko WM, Bissada NF (2008) An evidence-based analysis of periodontally accelerated orthodontic and osteogenic techniques: a synthesis of scientific perspective. Seminars Orthod 14: 305-316.

5. Sebaoun JD, Ferguson DJ, Wilcko MT, Wilcko WM (2007) Alveolar osteotomy and rapid orthodontic treatments. Orthod Fr 78: 217-225.

6. Kole H (1959) Surgical operations on the alveolar ridge to correct occlusal abnormalities. Oral Surg Oral Med Oral Pathol 12: 515-529.

7. Kole $\mathrm{H}$ (1959b) Surgical operations on the alveolar ridge to correct occlusal abnormalities. Oral Surg Oral Med Oral Pathol 12: 413-420.

8. Kole $H$ (1959c) Surgical operations on the alveolar ridge to correct occlusa abnormalities. Oral Surg Oral Med Oral Pathol 12: 277-288.

9. Wilcko WM, Wilcko MT, Bouquot JE, Ferguson DJ (2000) Accelerated orthodontics with alveolar reshaping. J Ortho Practice 10: 63-70.

10. 7. Suya H (1991) Corticotomy in orthodontics. In: Hosl E, Baldauf A (1997) Mechanical and Biological Basis in Orthodontic Therapy. Huthig Buch Verlag Heidelberg, Germany: 207-226.

11. Sebaoun JD, Kantarci A, Turner JW, Carvalho RS, Van DykeTE, et al. (2008) Modeling of trabecular bone and lamina dura following selective alveolar decortication in rats. J Periodontol 79: 1679-1688.

12. Nowzari H, Yorita FK, Chang HC (2008) Periodontally accelerated osteogenic orthodontics combined with autogenous bone grafting. Compend Contin Educ Dent 29: 200-206.

13. Ozturk M, Doruk C, Ozec I, Polat S, Babacan H, et al. (2003) Pulpal blood flow: effects of corticotomy and midline osteotomy in surgically assisted rapid palatal expansion. J Craniomaxillofac Surg 31: 97-100.

14. Lee JK, Chung KR, Baek SH (2007) Treatment outcomes of orthodontic treatment, corticotomy-assisted orthodontic treatment, and anterior segmental osteotomy for bimaxillary dentoalveolar protrusion. Plast Reconstr Surg 120 1027-1036. 